\title{
REVIEW
}

\section{Towards an Effective and Safe Treatment of Inflammatory Pain: A Delphi-Guided Expert Consensus}

\author{
Giustino Varrassi (1) - Eli Alon - Michela Bagnasco - Luigi Lanata • \\ Victor Mayoral-Rojals - Antonella Paladini - Joseph V. Pergolizzi · \\ Serge Perrot $\cdot$ Carmelo Scarpignato $\cdot$ Thomas Tölle
}

Received: May 13, 2019 / Published online: August 16, 2019

(C) The Author(s) 2019

\section{ABSTRACT}

Objective: The clinical management of inflammatory pain requires an optimal balance between effective analgesia and associated safety risks. To date, mechanisms associated with inflammatory pain are not completely understood because of their complex nature and the involvement of both peripheral and central mechanisms. This Expert Consensus document is intended to update clinicians about evolving areas of clinical practice and/or

Enhanced Digital Features To view enhanced digital features for this article go to https://doi.org/10.6084/ m9.figshare.9211526.

G. Varrassi $(\square)$

Paolo Procacci Foundation, Rome, Italy

e-mail: giuvarr@gmail.com

G. Varrassi

President of World Institute of Pain (WIP),

Winston-Salem, NC, USA

E. Alon

University of Zurich, Zurich, Switzerland

M. Bagnasco · L. Lanata

Medical Affairs Department, Dompé Farmaceutici

SpA, Milan, Italy

V. Mayoral-Rojals

University of Belvitge, Barcellona, Spain available treatment options for the management of patients with inflammatory pain.

Method: An international group of experts in pain management covering the pharmacology, neurology and rheumatology fields carried out an independent qualitative systematic literature search using MEDLINE, EMBASE and the Cochrane Central Register of Controlled Trials. Results: Existing guidelines for pain management provide recommendations that do not satisfactorily address the complex nature of pain. To achieve optimal outcomes, drug choices should be individualized to guarantee the best match between the characteristics of the patient and the properties of the medication. NSAIDs represent an important prescribing choice in the management of inflammatory
A. Paladini
Department of MESVA, University of L'Aquila,
L'Aquila, Italy
J. V. Pergolizzi
NEMA Research Inc, Naples, FL, USA
S. Perrot
Descartes University and Cochin-Hotel Dieu
Hospital, Paris, France
C. Scarpignato
University of Parma, Parma, Italy
T. Tölle
University of Munich, Munich, Germany 
pain, and the recent results on paracetamol question its appropriate use in clinical practice, raising the need for re-evaluation of the recommendations in the clinical practice guidelines.

Conclusions: Increasing clinicians' knowledge of the available pharmacologic options to treat different pain mechanisms offers the potential for safe, individualized treatment decisions. We hope that it will help implement the needed changes in the management of inflammatory pain by providing the best strategies and new insights to achieve the ultimate goal of managing the disease and obtaining optimal benefits for patients.

Funding: Dompé Farmaceutici SPA and Paolo Procacci Foundation.

Keywords: Adjuvant drugs; Inflammation; Inflammatory pain; Neurogenic pain; Neuroinflammation; NSAIDs; Opioids; Pain

\section{INTRODUCTION}

Pain represents the most commonly reported health problem in the clinical setting as well as in the general population. Its inadequate control is a persistent, major, unmet need in medicine worldwide $[1,2]$. Acute pain is activated by a specific disease or injury, while chronic pain is recognized as a disease in its own right $[3,4]$. The most common types of acute and chronic pain based on etiology and clinical presentation include nociceptive, inflammatory and neuropathic syndromes. Nociceptive pain, frequently accompanied by inflammation, occurs because of stimulation of unaltered nociceptors by external stimuli and/or release of pain-causing substances [5]. In women, it is significantly influenced by the menstrual cycle [6]. Usually, in inflammatory pain, the tissue damage is responsible for the activation of inflammatory mediators implicated in the potentiation of pain. The inflammatory process has a protective role by activating the immune system. This adaptive function is one that can exacerbate painful symptoms. The inflammatory cascade is complex but the discontinuation of the inflammatory process represents a potential target to reduce painful conditions $[7,8]$. Inflammatory pain reflects sensitization mechanisms, whose consequences are hyperalgesia and/or allodynia. Sensitization can occur at both the peripheral and central level [5]. Its origin is also mediated by mast cells and neuroinflammation [8]. When acute pain progresses through central sensitization to chronic pain, inflammation and inflammatory pain may persist [9] and become chronic pain [10].

Recent population-based surveys conducted in major European countries have found that chronic pain was reported in $25-35 \%$ of adults $[1,11,12]$. A study showed that $79 \%$ of patients suffering from chronic pain continued to report they were suffering from pain after 4 years [13]. Lower back and neck pains are the leading global causes of disability in Europe [14]. The presence of neuropathic pain is associated with an increased disease burden in chronic pain patients, dramatically affecting their quality of life and direct medical costs [11].

Detailed recommendations on the use of various treatments used to manage pain have been published by multiple national and international scientific societies [15]. Some guidelines are related to specific pain conditions including osteoarthritis [16], fibromyalgia [17], low back pain [18] and neuropathic pain [19], and some also focus on special populations like the elderly [20]. In all cases, graded approaches are recommended together with individualized management [21-23]. The World Health Organization (WHO) "pain ladder" for analgesics has guided clinicians in managing pain for many years [24]. However, this ladder has repeatedly been challenged $[25,26]$, and its relevance to inflammatory pain is minimal. The International Association for the Study of Pain (IASP) classification of analgesics [27], based on how drugs modify pathophysiologic pain mechanisms, may be most appropriate for the management of acute and chronic pain conditions.

This Expert Consensus Document is intended to advise physicians of the opinion of a Pain International Expert Group concerning chronic inflammatory pain management. It has been developed by reviewing the current literature on inflammatory pain and its pharmacologic 
management to provide evidence-based clinical recommendations for appropriate treatment.

\section{METHODS}

This study was based on an initial project of the Paolo Procacci Foundation (PPF), a non-profit organization, whose purpose is the study of pain management. An international group of experts in pain management, pharmacology, neurology and rheumatology, constituting the Expert Group, was put together to discuss the topic. The Members were selected by the Scientific Committee of the PPF based on their specialty, scientific experience and previous work for scientific societies and/or for similar projects. All were experienced with studies based on Delphi methodology, review articles and meta-analysis and had at least 10 years' experience in pain management. A modified Delphi model was used. The first meeting objective was to make clear the finality of the Expert Group and identify the most relevant area of interest, which would have represented the topics discussed in the final document. The Expert Group agreed to critically assess published evidence on the management of inflammatory pain and to develop practical recommendations on the pharmacologic treatment of inflammatory pain. The initial discussion was based on each individual experience and was focused on the acceptance of the proposed relevant areas, agreed upon if they got at least $70 \%$ approval by the panelists, using a 11-point numerical rating scale $(0-10)$. The initial proposals are listed in Table 1.

At the end of the first meeting, the accepted proposals were distributed, based on the specific background of the experts. The authors are experts and key opinion leaders in their field and have expert familiarity with the relevant peer-reviewed literature. Experts were asked to consider relevant articles of high quality (clinical trials, systematic reviews, meta-analyses only) published in English in the last 10 years. Further bibliographic information was obtained from the articles chosen, when necessary, for older sources of value. For each topic, a draft report was prepared and circulated among all
Table 1 List of initial proposals

1 Inflammation

2 Peripheral inflammation

3 Inflammatory pain

4 Neuroinflammation and neurogenic pain

5 Postoperative pain

6 Traumatic pain

7 Clinical conditions of inflammatory pain

8 Pain management

9 Pharmacologic approaches to inflammatory pain

10 Peripheral vs. central mechanisms of currently available analgesics

11 Safety issues in at-risk patients

12 Ideal analgesics for inflammatory pain and possible future developments

the members of the Expert Group. Following preparation of the revised draft, each topic was addressed to the Core Writing Panel (JVP and GV) who prepared the first draft of the entire paper that was then examined during a second meeting of the group. An anonymous vote was taken in the second meeting.

During this meeting, each single selected topic was thoroughly discussed. Each statement concerning the summary of current evidence was evaluated based on level of evidence (Table 2), refined and approved by at least seven

Table 2 Level of evidence for the selected and discussed papers

Level of evidence

A Data derived from multiple randomized clinical trials and/or review article and meta-analysis

B Data derived from a single randomized clinical trial or nonrandomized studies

C Consensus opinion of experts 
members of the panel, regarding both content and wording. Only papers approved as level A or level B were accepted for this "expert opinion." The Core Writing Panel then incorporated all the suggestions raised during the second meeting and prepared the final draft. An updated literature search was performed and the most recent available evidence included.

This revised document was then sent to all the members of the Expert Group for the final review. Any changes resulting from last comments received by the experts were shared and included by general agreement among all the member of the group, resulting in the final version of this expert opinion paper.

This is a review and Expert Consensus document based on previously conducted studies and does not contain any studies with human participants or animals performed by any of the authors.

\section{RESULTS}

The initial list of proposed topics (Table 1), at the end of the first meeting, was only partially approved (Table 3), and only seven topics to

Table 3 Approved topics for discussion

\begin{tabular}{lll}
\hline 1 & Inflammation & $82 \%$ \\
2 & Peripheral inflammation & $74 \%$ \\
3 & Inflammatory pain & $41 \%$ \\
4 & Neuroinflammation and neurogenic pain & $73 \%$ \\
5 & Postoperative pain & $55 \%$ \\
6 & Traumatic pain & $55 \%$ \\
7 & Clinical conditions of inflammatory pain & $71 \%$ \\
8 & Pain management & $67 \%$ \\
9 & Pharmacologic approaches to inflammatory & $84 \%$ \\
& pain & \\
10 & Peripheral vs. central mechanisms of currently & $72 \%$ \\
& available analgesics & $88 \%$ \\
11 & Safety issues in at-risk patients & $51 \%$ \\
12 & Ideal analgesics for inflammatory pain and & \\
$\quad$ possible future developments \\
\hline
\end{tabular}

discuss were agreed upon with $>70 \%$ : inflammation; peripheral inflammation; neuroinflammation and neurogenic pain; clinical conditions of inflammatory pain; pharmacologic approaches to inflammatory pain; peripheral versus central mechanisms of currently available analgesics; safety issues in atrisk patients.

\section{Inflammation}

Inflammation is a complex coordinated cascade of events in response to noxious stimuli [28]. As an adaptive response, inflammation offers rapid response to injury by promoting repair while protecting the damaged tissue [28]. At the same time, the inflammatory response may itself damage host tissue and cause organ dysfunction $[8,29]$. A review points out that the fundamental problem with inflammation is not how often it starts, but how often it fails to subside [30]. Non-resolving inflammation is one of the principal contributors to the medical burden and is involved in many chronic diseases [9]. Inflammation is particularly insidious where the peripheral and central nervous systems are involved ('neuroinflammation'), playing an important role in the pathogenesis of acute and chronic pain [31] as well as chronic neurodegenerative diseases [32-34] and neuropsychiatric illness [35, 36].

\section{Peripheral Inflammation}

Acute peripheral inflammation occurs after injury and/or infection, and it may be associated with acute inflammatory pain. After tissue damage, local macrophages release mediators that result in the so-called inflammatory response. Inflammatory mediators acidify the tissue, which activates nociceptive primary afferent neurons and lowers their signaling thresholds. These conditions increase the sensation of pain, both peripherally and centrally [37]. Both peripheral and central mechanisms have been identified as contributing to endogenous analgesia during inflammation $[37,38]$. These endogenous analgesic compounds include opioid peptides, 
endocannabinoids, somatostatin and antiinflammatory cytokines $[8,9,38,39]$. The activation of peripheral nociceptive $C$ and $A \delta$ fibers of primary afferent neurons, by several proinflammatory mediators such as histamine, serotonin, $\mathrm{H}^{+}$and cytokines, gives rise to action potentials that are conducted to the dorsal horn of the spinal cord. Subsequently, through several neuronal pathways, the nociceptive information can reach the higher brain centers including the thalamus and cortex [40].

\section{Neuroinflammation and Neurogenic Pain}

The term "neurogenic inflammation" defines the inflammatory response observed following the release of proinflammatory mediators from peripheral terminals of activated primary (afferent) sensory neurons [41]. Mechano-insensitive, but heat- and chemo-sensitive, C nociceptors are responsible for the neurogenic vasodilation in human skin [42]. These sensory receptors ending in the dorsal horn of the spinal cord release neurotransmitters and neuromodulators in response to peripheral noxious stimuli [43]. As a result of local depolarization, the nociceptive sensory neurons release proinflammatory mediators in the periphery, which produce vasodilatation and edema. They can recruit and activate immune cells as well as adaptive immune cells, which, together with the mediators released from the immune cells, participate in the phenomenon of neurogenic inflammation [41, 44, 45]. Calcitonin gene-related peptide, substance $\mathrm{P}$, and several other neuropeptides are the main mediators responsible for the sequence of pathogenic events leading to neurogenic inflammation [46]. The stimuli influencing neurogenic inflammation activate the transient receptor potential (TRP) ion channels and the purinergic (P2X) receptors, which play a crucial role in the development of inflammation and perception of pain. Therefore, ligands to these receptors or drugs able to counteract proinflammatory molecules may represent promising avenues in the management of inflammatory pain. The importance of this topic has been recently reviewed with the focus on chronic degenerative joint pain [8].
Recent evidence suggests that triggering the combined actions of neurons and immune/vascular cells in the central nervous system (CNS) may be associated with neuronal activity, exhibiting a profile similar to other neuroinflammatory states. The term "neurogenic neuroinflammation" was then proposed to define inflammatory responses triggered by neuronal activity in the CNS. It was postulated that neurogenic neuroinflammation might have useful effects associated with regeneration processes. In this context, maladaptive responses may arise when neurogenic neuroinflammation persists or spreads, becoming markedly relevant in conditions such as pain or epilepsy $[47,48]$.

\section{Clinical Conditions of Inflammatory Pain}

Acute postoperative pain, initially due to tissue lesions, soon afterward becomes an expression of inflammatory processes activated by the neuromediators and mast cell activity [9, 39-41]. Hence, management of postoperative pain is possible only if its inflammatory component is treated.

Osteoarthritis (OA) is a disorder characterized by the progressive damage of the articular cartilage, associated with new osteophyte formation, mild synovitis and synovial membrane inflammation [8], where cross-talk between articular cartilage and subchondral bone represents the backbone of joint disease [49]. Osteoarthritic joints are associated with peripheral and central pain sensitization [50]. Rheumatoid arthritis (RA) is a progressive inflammatory disease that mainly affects the peripheral joints and often causes the destruction of cartilage and bone [51]. It is commonly associated with pain and swelling of the small joints. Fibromyalgia, recently suggested as a "nociplastic" pain [10], seems also caused by a persistent inflammatory condition [52].

\section{Pharmacologic Approaches to Inflammatory Pain}

Pharmacologic treatment of pain is complex and requires specific education and clinical 
training since there are important clinical considerations that physicians may face in daily practice. To achieve optimal outcomes, prescribing decisions should be individualized to ensure the best match between the drug properties and the patient's characteristics.

Despite the frequency and severity of pain, the available pharmacologic options for pain treatment are not satisfactory, and most of the analgesics currently in use are quite old. Drugs for pain fall into four main categories: (1) weak analgesics, (2) non-steroidal antiinflammatory drugs (NSAIDs), (3) opioids and (4) adjuvant drugs (Table 4). Different drugs with different mechanism(s) of action may be combined for enhanced efficacy.

\section{Weak Analgesics}

After a short discussion on the topic, paracetamol is the most widely used of the "weak analgesics" and hence the only one mentioned in this document. Its mechanism of action has not been elucidated yet. The analgesic and antipyretic actions of paracetamol are comparable to those of aspirin, but paracetamol is devoid of any antiinflammatory activity. In many guidelines, paracetamol is still considered the analgesic of first choice, and it is usually the preferred drug for long-term treatment. A recent review of clinical guidelines for the management of non-specific low back pain pointed out that paracetamol is not recommended as the

Table 4 Drugs used in inflammatory pain pharmacologic treatment

\begin{tabular}{ll}
\hline Weak analgesics & Paracetamol \\
\hline NSAIDs & Ibuprofen, diclofenac, ketoprofen \\
Opioids & \\
Adjuvant drugs & $\begin{array}{c}\text { Antidepressant, antiepileptic } \\
\text { medications, corticosteroids, } \\
\text { colchicine, neurotrophine, biologic } \\
\text { drugs }\end{array}$ \\
& \\
Analgesic drug & \\
combinations & \\
\hline
\end{tabular}

first-choice analgesic, as it was for many years, and NSAIDs are preferable [53]. The broad utilization of paracetamol for pain management is mainly due to its allegedly favorable safety profile [especially on the gastrointestinal (GI) tract] and low cost. New evidence increasingly points out a cardiovascular (CV) and GI safety concern in addition to the drug's well-documented hepatotoxicity [54]. Paracetamol is frequently combined with opioids for pain relief, and even if combination products offer beneficial incremental pain relief, available clinical studies have demonstrated that this was not superior to NSAIDs in the control of post-surgery pain and correlated with more adverse events [55].

Some studies demonstrated that paracetamol is less effective in pain relief compared with antiinflammatory drugs in patients with $\mathrm{OA}$ [56-58]. A double-blind, randomized, placebocontrolled trial investigated the efficacy of paracetamol in patients with acute low back pain [59]. No differences between treatments were found for the primary outcome, underlining that paracetamol did not improve recovery compared with placebo. The findings of these studies suggest that weak analgesics might not be important in the management of acute low-back pain and other OA pathologies, especially when an inflammatory component is present. Their results indicated that paracetamol should not be recommended as monotherapy in patients with acute OA. Similarly, a systematic literature review on paracetamol efficacy showed that there are only limited long-term data on paracetamol efficacy in patients with chronic pain; available studies were conducted in OA patients, which supported the negligible efficacy of the treatment [60]. In line with these data, a recent systematic literature review, specifically designed to evaluate the existing evidence regarding the safety profile of long-term paracetamol assumption, indicated that paracetamol is associated with an increased dose-dependent toxicity at standard analgesic doses [54]. This includes a dose-response relationship between paracetamol at standard analgesic doses and increasing incidence of mortality, CV, GI and renal adverse events in the general adult population. 
Consequently, recent National Institute for Health and Care Excellence (NICE) guidance for the management of low back pain discourages the use of paracetamol alone as an analgesic drug for this condition [61].

\section{NSAIDs}

NSAIDs are considered as first choice and effective drugs for inflammatory pain [56, 62, 63]. NSAIDs are: (1) analgesic, (2) antipyretic, (3) antiinflammatory and (4) platelet aggregation inhibitors. All actions are mediated by the same mechanism of action: they block prostaglandin production by inhibiting both forms of cyclooxygenase (COX1 and COX2) essential for the synthesis of prostaglandins (PGs) [64].

NSAIDs represent an important pharmacologic choice in the management of inflammatory pain. This class of drugs includes many compounds with clinically relevant differences regarding efficacy and safety. Among the many NSAIDs available, ibuprofen, diclofenac and ketoprofen remain the most frequently used [64]. Primary indications for NSAID treatment include postoperative pain, traumatic pain, acute arthritis, RA and other rheumatic disorders. Not all the NSAIDs have the same profile. Specifically, medication-related (i.e., pharmacokinetic properties, spectrum of efficacy against different types of pain) and patient-related (comorbidities, risk factors for potential adverse effects) characteristics need to be considered when choosing the right NSAID for the individual patient.

Ibuprofen is one of the most popular NSAIDs. It is a racemic mixture. $\mathrm{R}(-)$-ibuprofen inhibits leucocyte activation, neural activity and spinal transmission, thus contributing to the effects on inflammatory pain [65]. Recent evidence from large-scale clinical trials with the newer COX-2 inhibitors (coxibs), where this NSAID served as a comparator, has confirmed earlier studies, showing that ibuprofen has comparable therapeutic benefits as coxibs and non-selective NSAIDs [65]. Ibuprofen's potential to interfere with the antiplatelet effects of aspirin should enhance the caution in patients treated with aspirin for primary or secondary cardiovascular risk prevention [66].
Diclofenac has a degree of COX-2 selectivity similar to that of celecoxib. Diclofenac absorption may vary markedly because of potential precipitation under acidic conditions, inter-individual $\mathrm{pH}$ variability in the GI tract [67] and drug formulation, e.g., liquid-filled capsules of diclofenac showed an increased rate and consistency of absorption [68]. As with other NSAIDs, diclofenac is associated with renal, CV and GI toxicity, which is usually dose dependent. This agent is associated with an increased risk of $\mathrm{CV}$ adverse events, including thrombotic events, mainly explained by its COX-2 selectivity similar to coxibs [69].

Ketoprofen is a chiral 2-arylpropionic acid derivative NSAID with analgesic, antipyretic and antiinflammatory effects widely used for the management of pain associated with rheumatic and traumatic disorders [70]. Ketoprofen is marketed as a racemic mixture. Only the $\mathrm{S}$-enantiomer is responsible for its most relevant pharmacologic activities. Currently, ketoprofen is available on the market as ketoprofen lysinate. The salification allows for higher solubility than acid ketoprofen. This characteristic is associated with an improved pharmacokinetic profile; in particular after the oral administration of ketoprofen lysine salt, prompter and more complete absorption of the molecule has been observed with a high peak plasma concentration reached after $15 \mathrm{~min}$ vs. $60 \mathrm{~min}$ after administration of the corresponding free acid [70]. Furthermore, the improved solubility as well as bioavailability of ketoprofen lysine salt has the particular advantage of reducing the GI toxicity of the molecule, which is responsible for better gastrointestinal safety when used at the recommended dosages. Recent data have also provided clear evidence of its negligible effects on the gastric mucosa [71, 72].

Not all the NSAIDs have the same efficacysafety profile. In an old study [73], the clinical analgesic efficacy in a dental pain model compared the antiinflammatory activity of different NSAIDs. When the clinical efficacy of NSAIDs is plotted against the ratio of antiinflammatory and analgesic activities in experimental models, ketoprofen appears to be the best molecule among the different NSAIDs compared (Fig. 1). These data have been confirmed by a meta- 


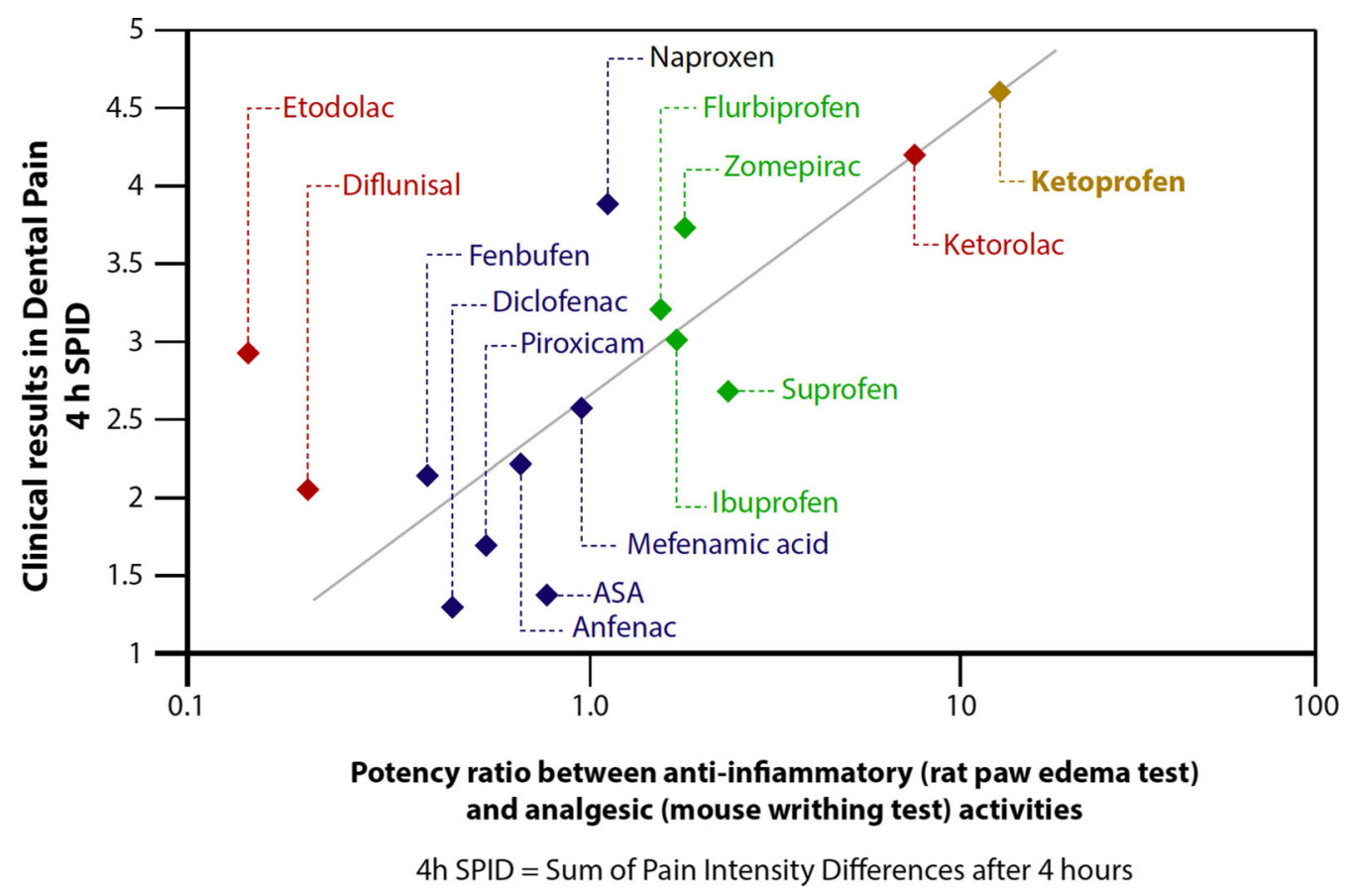

Fig. 1 Clinical and experimental evaluation of analgesic and antiinflammatory effects of several NSAIDs. Data extracted from $[73]$

analysis conducted on 13 randomized controlled trials [64]. The authors found that ketoprofen's efficacy in moderate-to-severe pain relief was significantly better compared with subjects on ibuprofen and/or diclofenac.

Since serious adverse effects may be associated with oral NSAIDs, their long-term use is not recommended. Topical NSAIDs have been shown to be beneficial from both the therapeutic and adverse effect perspectives and are increasingly recommended in treatment guidelines [74].

\section{Opioids}

Opioids are considered the most effective analgesics for cancer pain. The evidence is not as compelling for chronic non-cancer pain [75], even though their prescription has become frequent, especially in the USA, Canada and Australia. Opioids can act at different steps in the inflammatory cascade exerting their activity by binding to opioid receptors [76]. A review conducted to evaluate opioid efficacy for the treatment of chronic low back pain confirmed their effectiveness in the short term but emphasized the paucity of evidence in the long term [77]. The European League Against Rheumatism (EULAR) recommendations for the management of knee and hip OA underline the usefulness of opioids only when NSAIDs are poorly tolerated or inefficacious [78, 79]. The most recent NICE guideline for treatment of low back pain recommends: (1) oral NSAIDs for the shortest period of time feasible at the lowest but efficacious dose; (2) the use of a weak opioid in the case of patients who do not respond to or tolerate NSAIDs. The guideline emphasized that the effect of opioids for the treatment of chronic low back pain is too poor to be considered clinically relevant [61]. In any case, they should always be prescribed wisely [22].

\section{Adjuvant Drugs}

Antidepressant drugs: a bidirectional link among inflammation, chronic pain and depression is clear [80, 81]. Major depressive disorder (MDD) has been indicated to occur with inflammation, and patients suffering from MDD exhibit elevated levels of cytokines associated with inflammation. Proinflammatory 
agents appear to induce depression [82], and, conversely, a meta-analysis reported that antiinflammatory treatment reduced depressive symptoms [83]. Antidepressant drugs exert a broad range of pharmacologic actions and, in addition, may exert an antiinflammatory effect $[84,85]$.

Antiepileptic medications are frequently used as adjuvants for chronic painful conditions; in particular, they address neuropathic pain [86]. Many antiepileptic drugs have been demonstrated to be efficacious in the treatment of post- herpetic neuralgia and the treatment of trigeminal neuralgia, conditions with an inflammatory component [87]. Pregabalin demonstrated an antinociceptive effect in rats with facial inflammatory pain [88], but also in painful neuropathic conditions and fibromyalgia [89].

Corticosteroids are often used to treat painful conditions, including, but not limited to, inflammatory pain [90]. The EULAR guidelines recommend corticosteroids as a safe and effective alternative for treating pain associated with crystal-induced arthritic conditions when NSAIDs are not well tolerated [91].

Colchicine is a natural antimitotic alkaloid extensively used to treat gout. As part of the inflammatory response, microtubules are formed, which generate inflammatory mediators [92]. Hence, colchicine can be an effective treatment to reduce pain and inflammation of crystal-induced arthritis associated with intense inflammatory processes triggered by crystal deposits in the synovial tissues [92]. Colchicine also downregulates multiple proinflammatory pathways $[93,94]$. Pretreatment with colchicine blocks the processing of interleukin 1-beta (IL$1 \beta)$, although colchicine does not affect the activation of IL-1 $\beta$ via extracellular adenosine diphosphate (ATP), which suggests that colchicine acts upstream of inflammasome activation [95].

Neurotrophin (NTP) is marketed in Asia for managing chronic painful conditions associated with inflammation and acts by suppressing descending pain pathways, although the exact mechanism of action remains to be elucidated. It has been hypothesized that NTP works by suppressing inflammatory signaling and cell death pathways that had been induced by IL-1 $\beta$ and tumor necrosis factor-alpha (TNF- $\alpha$ ) in liver cells [96].

Biologic drugs: IL-1 blockage with biologic drugs may help inflammatory pain management. Anakirna, an IL-1 receptor antagonist, significantly reduced gout pain 3 days after initial injection [97]. Rilonacept and canakinumab are also IL-1 inhibitors that have been effective in reducing the inflammatory pain associated with gout [98]. Recent discoveries underline the importance of early treatment of OA with monoclonal antibodies (mAb), known as disease-modifying anti-OA drugs (DMOAD) [99-102]. Nerve growth factor (NGF) appears to play a role in pain signaling associated with OA. MAbs that might target NGF include tanezumab, fulranumab and bevacizumab [97]. Future clinical trials are needed to assess the clinical efficacy of these agents with focus on targeting specific phenotypes.

\section{Analgesic Drug Combinations}

Despite the availability of numerous pharmacologic options, the treatment of pain remains unsatisfactory mainly because of the burden of adverse events and to the heterogeneity of disease [103]. Research on the optimal use and combination of existing drugs represents a useful approach to more effective pain management. Combining drugs might be useful in that the single drugs can be administered at lower doses than in monotherapy, and, moreover, combination of two or more drugs belonging to different classes may increase therapeutic effects. The combination of codeine plus paracetamol did not show any superiority over NSAIDs in the treatment of postoperative inflammatory pain [55]. The option of combining an effective NSAID with weak opioids represents a valuable alternative [104]. Fixed dose combination of tramadol and dexketoprofen has recently been demonstrated advantageous in head-to-head comparison with the combination of tramadol and paracetamol [105]. 


\section{Peripheral Versus Central Mechanisms of Currently Available Analgesics}

Different cellular and molecular pathways are involved in the development of different types of pain. Some of these mechanisms can operate both alone or in combination, resulting in different types of pain [106]. Analgesic drugs may have both peripheral and central activity. For instance, opioids exert their analgesic and antiinflammatory activity at both the peripheral and central level [107].

The antinociceptive effect of NSAIDs is mainly associated with their common mechanism of action, the inhibition of COX-mediated prostaglandin synthesis [56, 64, 108]. Inhibition of prostaglandin synthesis at both at the peripheral and central levels by NSAIDs is associated with the normalization of the pain threshold, which may have been elevated because of inflammation. Several factors are involved in the extent of the contribution of peripheral and central mechanisms to the global NSAID antinociceptive action comprising: (1) the physical-chemical characteristics of the selected NSAID; (2) the site of the target of NSAID action; (3) the NSAID uptake and disposition at the target site.

To study the effect of a molecule inside the brain, it is important to evaluate its concentration in the cerebrospinal fluid (CSF) showing that the drug has crossed the blood-brain barrier (BBB). However, the NSAID levels in human CSF have not been comprehensively evaluated [109]. Hence, only few data on the NSAID levels in the CNS have been published. Recently, some data appeared on the cerebrospinal fluid distribution of dexketoprofen and etoricoxib [110]. Ketoprofen, like other NSAIDs, exerts its action at the peripheral and central sites by inhibiting both nitric oxide (NO) and COX synthase in the brain [111, 112]. Gynther et al. [113] assessed the brain uptake of ketoprofen-lysine and demonstrated a more rapid ketoprofen-lysine brain uptake compared with ketoprofen. These results confirm that the salification of ketoprofen furthers a more rapid cross of the BBB. Moreover, ketoprofen lysine salt reaches its maximum plasma peak rapidly, concomitantly with its presence in the CNS [113]. This particular rapidity in crossing the BBB explains the rapid onset of action well recognized for ketoprofen lysine salt compared with the acid ketoprofen and other NSAIDs. The overall antinociceptive action of these compounds may show a more pronounced central component compared with other NSAIDs due to specific pharmacokinetic characteristics. This hypothesis is supported by a recent double-blind, randomized, placebo-controlled study aimed at assessing the cerebral response to ibuprofen in pre-/postsurgical states [114].

\section{Safety Aspects in At-Risk Patients}

Although NSAIDs are characterized by welldocumented efficacy, their use is associated with different adverse effects including the $\mathrm{CV}$ and GI system, skin, liver and kidneys [53, 56]. The most common are on the GI system. The identification of factors that might predict the risk of GI complications associated with NSAIDs is crucial [115]. Among the documented risk factors, the most relevant are age and a history of peptic ulcer, together with the characteristics of the drugs (Fig. 2). Coxibs have a better upper GI safety profile than traditional NSAIDs $[115,116]$. There are data on higher risk factors of GI bleeding for racemic ketoprofen compared with other traditional NSAIDs [117]. These data may be affected by dosages. In fact, in the referred study ketoprofen was frequently used at dosages higher than recommended ( $\geq 200 \mathrm{mg} /$ day) [118]. For ketoprofen, GI toxicity is dose-related in a non-linear fashion, and for this reason it is important to administer the drug within the therapeutic dosage [119]. Further insights into the GI risk associated with NSAID use were gained from a multicenter casecontrol study including 2813 cases of upper GI bleeding in adult patients and 7193 matched controls [120]. For the first time, it has been clearly demonstrated that GI risk was strictly correlated with the individual drug and its dose. Doses of ibuprofen $\geq 1800 \mathrm{mg}$ showed a higher GI risk compared with a reduced dosage between 1200 and $1799 \mathrm{mg}$; in the same way, a ketoprofen dose $\leq 200 \mathrm{mg}$ appeared to be less gastro-toxic than previously thought. 


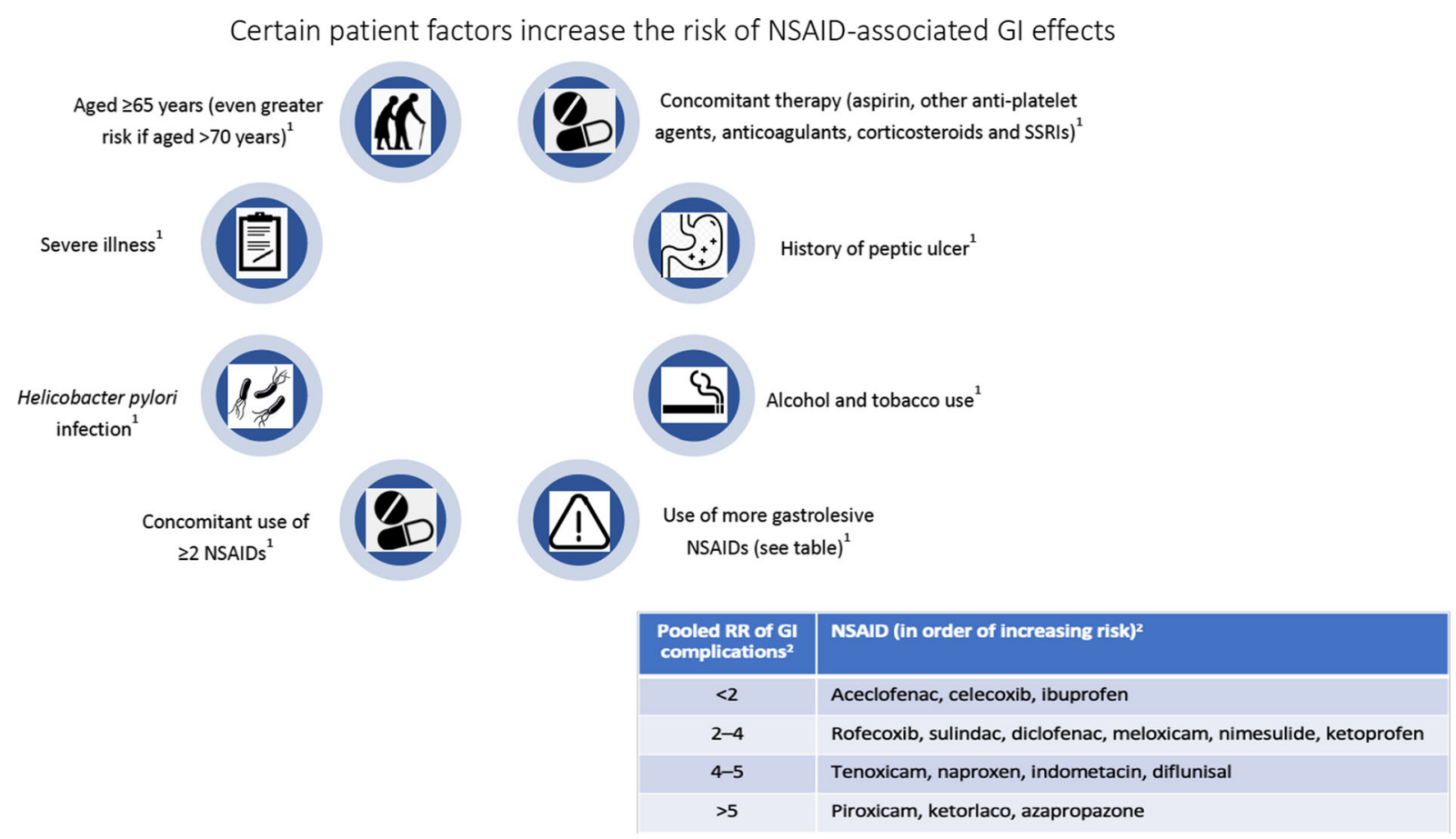

Fig. 2 Risk factors for NSAID-associated GI effects, including the relative risk (RR), were different for several NSAIDs. Redrawn from: 1. Salvo et al. [115]; 2.

Safety of analgesics represents an important aspect in the treatment of pain. Treatment nonadherence is a frequent problem in patients with pain [121], and the safety of drugs has resulted a reason of primary importance affecting compliance to prescribed therapy $[122,123]$. Since the GI toxicity observed with NSAID use still represents one of the main limitations in the management of pain, many studies have focused on the investigation of potential gastro-protective effects of specific NSAID formulations. Available preclinical and clinical studies described the key role of dietary amino acids including lysine in the prevention of intestinal disease and maintenance of the gut integrity [124]. An old preclinical study established a significant decrease of gastric ulcers in the group treated with ketoprofen lysine salt compared with the group of animals treated with the free acid, demonstrating better gastric tolerability of ketoprofen lysine salt vs. ketoprofen [125]. These data have never been denied. To elucidate the molecular mechanisms underlying this interesting gastro-protective
Castellsague et al. [117]. GI gastrointestinal, NSAID non-steroidal antiinflammatory drug, $R R$ relative risk, $S S R I$ selective serotonin reuptake inhibitor

effect of the L-lysine ketoprofen, Cimini et al. [71] studied the effects of L-lysine alone and associated with ketoprofen in an ethanol-gastric injury model, comparing these effects with those obtained with ketoprofen. They demonstrated that L-lysine in the ketoprofen molecule has a potent antioxidant effect, counteracts the increase of malondialdehyde (MDA) ethanolinduced inhibition and stimulates the production of endogenous gastro-protective proteins, showing a strong synergic effect between Llysine and ketoprofen [71]. Recent data from the same group have demonstrated that ketoprofen per se is responsible for a safer response of the gastric epithelium compared with ibuprofen [72]. Moreover, these results confirm that the protective effect exerted by lysine is associated with a marked regulation of oxidative stress signals, suggesting its better safety profile in patients with compromised gastric mucosa or more prone to experience a gastric mucosa injury [72].

A significant increased risk of upper GI bleeding has been observed with the concurrent 
use of non-selective NSAIDs or low-dose aspirin, but not coxibs, with aldosterone antagonists, anticoagulants and corticosteroids. However, the pharmacodynamic interactions between NSAIDs and low-dose aspirin may not be classified as class effect because not all NSAIDs interact with aspirin to the same extent. To date, only individual studies with heterogeneous designs are available. These studies suggest that the adverse interaction between individual NSAIDs and aspirin is subjected to molecular differences among compounds. In this context, recent reviews analyzed the drugdrug interactions between different NSAIDs and aspirin [126-128]. Ketoprofen does not interfere with antiplatelet activity, while ibuprofen and naproxen inhibit aspirin's antiplatelet effect $[127,128]$. For this reason, the US Food and Drug Administration (FDA) recommends that at least $8 \mathrm{~h}$ pass after ibuprofen ingestion before taking aspirin.

During the last years, the global adverse event profile of antiinflammatory drugs has been revised with particular focus on the adverse CV events observed with coxibs [56]. Recent data suggest that at least some non-selective NSAIDs may also increase the CV risk [129]. Among the traditional non-selective NSAIDs, minor differences in the CV safety profile have been observed and currently remain a central question for regulatory agencies and clinicians. When the CV safety issue is raised among NSAID users, it is important to pay attention to the duration and frequency of treatment. The risk of CV adverse events is small over a short period of treatment. In observational studies, the rates for adverse $\mathrm{CV}$ events are often lower than rates reported in randomized clinical trials (RCTs) because NSAID use in everyday practice is not as regular as it is in RCTs. Some drugs have a better safety profile, while others are more dangerous, especially when used at higher dosages. As a consequence, the FDA recommends that NSAIDs should be used at the lowest efficacious dose and for the shortest period of time [130].

A large study funded by the European Commission has been designed with the aim to assess CV safety in NSAIDs to develop novel treatment decision models [131]. The report of this study evaluated individual NSAIDs regarding acute myocardial infarction, heart failure and ischemic cerebrovascular accident presenting relative risk estimates and relative risks obtained from the included meta-analyses. Among the selected NSAIDs, ketoprofen, followed by meloxicam, celecoxib and naproxen, showed the lowest relative risk for ischemic cerebrovascular accidents.

A Danish nationwide case-time control study has investigated the association between NSAIDs and cardiac arrest [132]. The use of nonselective NSAIDs was related to an augmented risk of cardiac arrest in ibuprofen and diclofenac users. This finding was not detected in coxib or naproxen users. This study is affected by important flaws because of its limited documentation. Among others, it reports that $11 \%$ of people with cardiac arrest were using NSAIDs, but does not compare it with NSAID users in the general Danish population. In other words, if the actual use of NSAIDs in the normal population were $>11 \%$, the study might suggest that NSAID use reduces the incidence of cardiac arrest.

A case-population study conducted in seven countries evaluated the association between NSAID population event rates and acute liver failure leading to transplantation in adult subjects exposed to paracetamol or an NSAID within 30 days before the onset of clinical symptoms [133]. Event rates per million treatment-years were 1.59 for all NSAIDs, while for individual NSAIDs were 2.3, 1.9, 1.6 and 1.6 for ibuprofen, nimesulide, diclofenac and ketoprofen, respectively. The rate for acute liver failure leading to transplantation was two-fold higher in patients exposed to therapeutic doses of paracetamol versus NSAIDs users [133]. This is the first study documenting that paracetamol, known to be a hepatotoxic drug at supra-therapeutic levels, is associated with a risk higher than NSAIDs even at recommended dosages.

\section{DISCUSSION}

Inflammatory pain is a complex condition characterized by multiple mechanisms. Current knowledge of pain mechanisms and how they 
relate to different treatment options in the medical community needs improvement. The panel of experts reached specific considerations on inflammatory pain management. Existing pain guidelines must offer clinicians updated recommendations by considering evolving areas of clinical practice commonly available or novel to the practice community with particular focus on the multiple mechanisms involved in inflammatory pain. Physicians should realize that inflammatory pain is not limited to nociception and that non-nociceptive and central mechanisms are also key components of inflammatory pain. Additionally, recent data suggest that the triggering of combined actions of neurons and immune/vascular cells in the CNS may be associated with neuronal activity and possess a profile similar to other neuroinflammatory conditions. This process has been described as "neurogenic neuroinflammation" to define inflammatory responses triggered by neuronal activity. The unmet clinical needs of patients with inflammatory pain are evident, and greater agreement about the optimal treatment strategy for this condition is necessary with a focus on the individual patient's characteristics and the type of pain.

The pharmacologic treatment of pain requires specific education and training. To achieve optimal outcomes, drug choices should be individualized to guarantee the best match between the characteristics of the patient and the properties of the medication. In this context, the main characteristics of the ideal analgesic are:

- Good efficacy

- Reasonable safety

- Rapid onset of action

- Durable effect

- Ease of administration

- Easy to handle and well tolerated

- No tolerance and no risk for abuse/ dependence

- Minimal potential for drug-to-drug interactions

- Low cost, high benefit.

Among the many available pharmacologic options, paracetamol is not indicated in inflammatory pain, being devoid of any antiinflammatory action. NSAIDs are effective and frequently used medications. However, it is important to consider potential risks when prescribing these drugs, particularly in the elderly and patients at elevated GI or CV risk. In patients with both these risks, a non-selective NSAID alone may be suitable, and low doses for a short-duration treatment should be preferred to manage moderate-to-severe pain. For patients with low CV risk and high GI risk, a COX-2 selective inhibitor or non-selectiveNSAID combined with a PPI are associated with comparable safety on the upper GI tract. Based on the recent evidence, it appears that in clinical manifestations of inflammatory pain, such as low back pain and OA, a non-selective NSAID should be preferred over certain analgesics such as paracetamol; moreover, among NSAIDs, salified NSAIDs, such as ketoprofen with lysine, were demonstrated to have a favorable balance between efficacy and safety.

Looking at the future, new modalities to block the inflammatory process should be studied. The well-known antagonism of COX, with its efficacy and safety profile, should not remain a limited possibility for the clinicians involved in the treatment of inflammatory pain. Other aspects of the inflammatory cascade should become a target for new drugs and potentially block the inflammatory process and its consequences on the tissues. In this respect, it seems that the antagonism of the C5aR and/ or the mast cells would be promising, especially for neuroinflammation $[7,8]$. The future should reserve interesting surprises for physicians and guarantee a safer approach to patients with inflammatory pain.

\section{CONCLUSIONS}

Despite the availability of several analgesic options, the effective treatment of inflammatory pain is still a challenge for clinicians, and the balance between efficacy and safety aspects remains both crucial and difficult. Emerging evidence on the multiple mechanisms of inflammatory pain has given rise to a multimodal approach to treatment. NSAIDs represent an important prescribing choice in the 
management of inflammatory pain, raising up the need to re-evaluate the recommendations in the clinical practice guidelines.

Revised guidelines are essential to support clinicians in selecting more efficacious and safe treatment options for inflammatory pain. New and high-quality evidence is required to implement more specific and updated recommendations to improve treatment of inflammatory pain. It is now time to start with a specific process aimed at offering patients with inflammatory pain the safest and most cost-effective therapeutic options, thus preventing serious adverse effects that could affect quality of life and resource use in inflammatory pain patients. We believe that the recommendations presented in this article are a step in the right direction.

\section{ACKNOWLEDGEMENTS}

Funding. The study was supported by Dompé Farmaceutici SPA and Paolo Procacci Foundation, through unconditioned grants. The terms of the financial support from Dompé Farmaceutici SPA and Paolo Procacci Foundation included freedom for the authors to reach their own conclusions and an absolute right to publish the results of this work, irrespective of any conclusions reached. Dompé Farmaceutici SPA did not have any role in design, planning, or execution of the review. The journal's rapid service and open access fee were funded by Dompé Farmaceutici SPA.

Editorial Assistance. The authors wish to thank Jo Ann LeQuang of Leqmedical for English revision and additional editing of the paper. Her support was generously offered by NEMA Research Ltd.

Authorship. All named authors meet the International Committee of Medical Journal Editors (ICMJE) criteria for authorship for this article, take the responsibility for the integrity of the work as a whole, and have given their approval for this version to be published.
Disclosures. Eli Alon was a consultant of Dompé Farmaceutici SPA and Sanofi. Victor Mayoral-Rojals was a consultant for Dompé Farmaceutici SPA, Esteve, Ferrer, Gruenenthal, Kyowa Kirin, Menarini, Mundipharma, Pfizer, and Takeda. Antonella Paladini has served as a consultant for Molteni Farmaceutici. Joseph V. Pergolizzi has been a consultant for BDSI, Daiichi, Dompé Farmaceutici SPA, Enalare, Hikma, Neumentum, Salix, and US World MEDS. Joseph V. Pergolizzi is a member of the journal's Editorial Board. Serge Perrot served as a consultant for Astellas, Dompé Farmaceutici SPA, Gruenenthal, Menarini, Merk, MSD, Pfizer, and Sanofi. Carmelo Scarpignato served as a consultant for Dompé Farmaceutici SPA, Gruenenthal, Menarini, Molteni, Pfizer, Shionogi, and Takeda. Thomas Tölle was a consultant of: Air Liquide, Almiral, Dompé, Gruenenthal, Hexal, Lilly, Menarini, Mundipharma, Novartis, OrphanPharma, Pfizer, and TAD Pharma. Michela Bagnasco is an employee of Dompé Farmaceutica SPA. Luigi Lanata is an employee of Dompé Farmaceutica SPA. Giustino Varrassi served as a consultant for Abbott, Dompé Farmaceutici SPA, Malesci, Menarini, Molteni, Mundipharma, Shionogi, and Takeda. Giustino Varrassi is the Pain Management Section Editor for the journal.

Compliance with Ethics Guidelines. This article is based on previously conducted studies and does not contain any studies with human participants or animals performed by any of the authors.

Open Access. This article is distributed under the terms of the Creative Commons Attribution-NonCommercial 4.0 International License (http://creativecommons.org/licenses/ by-nc/4.0/), which permits any noncommercial use, distribution, and reproduction in any medium, provided you give appropriate credit to the original author(s) and the source, provide a link to the Creative Commons license, and indicate if changes were made. 


\section{REFERENCES}

1. Del Giorno R, Frumento P, Varrassi G, Paladini A, Coaccioli S. Assessment of chronic pain and access to pain therapy: a cross-sectional population-based study. J Pain Res. 2017;10:2577-84.

2. Pergolizzi JV, Paladini A, Varrassi G, Raffa R. Change pain: ever evolving — an update for 2016. Pain Ther. 2016;5:127-33.

3. Tracey I, Bushnell MC. How neuroimaging studies have challenged us to rethink: is chronic pain a disease? J Pain. 2009;10:1113-20.

4. European Pain Federation (EFIC). 2001. https:// www.europeanpainfederation.eu/about-efic/eficdeclaration-on-pain/.

5. Kidd BL, Urban LA. Mechanisms of inflammatory pain. Br J Anaesth. 2001;87:3-11.

6. Piroli A, Mattei A, Carta G, et al. Influence of the menstrual cycle phase on pain perception and analgesic requirements in young women undergoing gynecological laparoscopy. Pain Pract. 2018. https://doi.org/10.1111/papr.12727.

7. Brandolini L, Grannonico M, Bianchini G, Colanardi A, Sebastiani P, Paladini A, Piroli A, Allegretti M, Varrassi G, Di Loreto S. The novel C5aR antagonist DF3016A protects neurons against ischemic neuroinflammatory injury. Neurotox Res. 2019. https://doi.org/10.1007/s12640-019-00026-w (Epub ahead of print).

8. Fusco M, Skaper SD, Coaccioli S, Paladini A, Varrassi G. Degenerative joint diseases and neuroinflammation. Pain Pract. 2017;17:522-32.

9. Varrassi G, Fusco M, Coaccioli S, Paladini A. Chronic pain and neurodegenerative processes in elderly people. Pain Pract. 2015;15:1-3.

10. Nicholas M, Vlaeyen JWS, Rief W, Barke A, Aziz Q, Benoliel R, Cohen M, et al. The IASP classification of chronic pain for ICD-11: chronic primary pain. Pain. 2019;160:28-37. https://doi.org/10.1097/j. pain.0000000000001390.

11. Langley P, Müller-Schwefe G, Nicolau A, Liedgens H, Pergolizzi J, Varrassi G. The societal impact of pain in the European Union: health-related quality of life and healthcare resource utilization. J Med Economics. 2010;13:571-81.

12. Leuter C, Piroli A, Marinangeli F, Paladini A, Tudini M, Varrassi G. Care strategies and therapeutic pathways for chronic pain patients in Abruzzo Region, Italy. Ann Ig. 2017;29:63-72. https://doi. org/10.7416/ai.2017.2133.
13. Elliott AM, Smith BH, Hannaford PC, Smith WC, Chambers WA. The course of chronic pain in the community: results of a 4-year follow-up study. Pain. 2002;99:299-307.

14. Vos T, Allen C, Arora M, et al. Global, regional, and national incidence, prevalence, and years lived with disability for 310 diseases and injuries, 1990-2015: a systematic analysis for the Global Burden of Disease Study 2015. Lancet. 2016;388:1545-602.

15. Ambrosio F, Finco G, Mattia C, Mediati R, Paoletti F, Coluzzi F, Piacevoli Q, Savoia G, Amantea B, Aurilio C, Bonezzi C, Camaioni D, Chiefari M, Costantini A, Evangelista M, Ischia S, Mondello E, Polati E, Raffaeli W, Sabato AF, Varrassi G, Visentin M, Alampi D, Tufano R. SIAARTI recommendations for chronic non-cancer pain. Min Anestesiol. 2006;72:859-80.

16. Hochberg MC, Altman RD, April KT, et al. American College of Rheumatology 2012 recommendations for the use of nonpharmacologic and pharmacologic therapies in osteoarthritis of the hand, hip, and knee. Arthritis Care Res (Hoboken). 2012;64:465-74.

17. MacFarlane GJ, Kronisch C, Dean LE, et al. EULAR revised recommendations for the management of fibromyalgia. Ann Rheum Dis. 2017;76:318-28.

18. Chou R, Qaseem A, Snow V, et al. Diagnosis and treatment of low back pain: a joint clinical practice guideline from the American College of Physicians and the American Pain Society. Ann Intern Med. 2007;147:478-91.

19. Finnerup NB, Attal N, Haroutounian S, et al. Pharmacotherapy for neuropathic pain in adults: a systematic review and meta-analysis. Lancet Neurol. $2015 ; 14: 162-73$.

20. Paladini A, Fusco M, Coaccioli S, Skaper SD, Varrassi G. Chronic pain in the elderly: the case for new therapeutic strategies. Pain Physician. 2015;18:E863-76.

21. Dowell D, Haegerich TM, Chou R. CDC guideline for prescribing opioids for chronic pain-United States, 2016. JAMA. 2015;315:1624-45.

22. O'Brien T, Christrup LL, Drewes AM, et al. European Pain Federation position paper on appropriate opioid use in chronic pain management. Eur J Pain. 2017;21:3-19.

23. Perrot S, Javier RM, Marty M, Le Jeunne C, Laroche F. Antidepressant use in painful rheumatic conditions. Rheum Dis Clin N Am. 2008;34:433-53.

24. WHO guidelines for the pharmacological and radiotherapeutic management of cancer pain in 
adults and adolescents. Geneva: World Health Organization; 2018. ISBN-13: 978-92-4-155039-0.

25. Eisenberg E, Marinangeli F, Birkhahn J, Paladini A, Varrassi G. Time to modify the WHO analgesic ladder. Pain clinical updates [Internet]. 2005; 13(5) 1-4. https://www.iasp-pain.org/PublicationsNews/ NewsletterIssue.aspx?ItemNumber=2121.

26. Azevedo Sao Leao Ferreira K, Kimura M, Jacobsen Teixeira M. The WHO analgesic ladder for cancer pain control, twenty years of use. How much pain relief does one get from using it? Support Care Cancer. 2006;14:1086-93.

27. Beaulieu P, Lussier D, Porreca F, Dickenson A. Pharmacology of pain. [Internet]. International Association for the Study of Pain (IASP). 2010. http://ebooks.iasp-pain.org/pharmacology_of_pain.

28. Machelska H, Schopohl JK, Mousa SA, Labuz D, Schaefer M, Stein C. Different mechanisms of intrinsic pain inhibition in early and late inflammation. J Neuroimmunol. 2003;141:30-9.

29. Castellheim A, Brekke OL, Espevik T, Harboe M, Mollnes TE. Innate immune responses to danger signals in systemic inflammatory response syndrome and sepsis. Scand J Immunol. 2009;69:479-91.

30. Nathan C, Ding A. Nonresolving inflammation. Cell. 2010;140:871-82.

31. Myers RR, Campana WM, Shubayev VI. The role of neuroinflammation in neuropathic pain: mechanisms and therapeutic targets. Drug Discov Today. 2006;11:8-20.

32. Freeman LC, Ting JP. The pathogenic role of the inflammasome in neurodegenerative diseases. J Neurochem. 2016;136(Suppl 1):29-38.

33. McGeer PL, McGeer EG. The amyloid cascade-inflammatory hypothesis of Alzheimer disease: implications for therapy. Acta Neuropathol. 2013;126:479-97.

34. Iadecola C, Anrather J. The immunology of stroke: from mechanisms to translation. Nat Med. 2011;17:796-808.

35. Castanon N, Luheshi G, Layé S. Role of neuroinflammation in the emotional and cognitive alterations displayed by animal models of obesity. Front Neurosci. 2015;9:229.

36. Najjar S, Pearlman DM, Alper K, Najjar A, Devinsky O. Neuroinflammation and psychiatric illness. J Neuroinflammation. 2013;10:43.
37. Hua S, Cabot PJ. Mechanisms of peripheral immune-cell-mediated analgesia in inflammation: clinical and therapeutic implications. Trends Pharmacol Sci. 2010;31:427-33.

38. Stein C. Opioids, sensory systems and chronic pain. Eur J Pharmacol. 2013;716(1-3):179-87.

39. Zhang C, Ward J, Dauch JR, Tanzi RE, Cheng HT. Cytokine-mediated inflammation mediates painful neuropathy from metabolic syndrome. PLoS One. 2018;13(2):e0192333. https://doi.org/10.1371/ journal.pone.0192333.

40. Yaksh TL, Woller SA, Ramachandran R, Sorkin LS. The search for novel analgesics: targets and mechanisms. F1000Prime Rep. 2015;7:56.

41. Severini C, Improta G, Falconieri-Erspamer G, Salvadori $S$, Ersparmer V. The tachykinin peptide family. Pharmacol Rev. 2002;54:285-322.

42. Schmelz M, Michael K, Weidner C, Schmidt R, Torebjork HE, Handwerker HO. Which nerve fibers mediate the axon reflex flare in human skin? NeuroReport. 2000;11:645-8.

43. Zhang X, Bao L. The development and modulation of nociceptive circuitry. Curr Opin Neurobiol. 2006;16:460-6.

44. Hosoi J, Murphy GF, Egan CL, et al. Regulation of Langerhans cell function by nerves containing calcitonin gene-related peptide. Nature. 1993;363:159-63.

45. Rosa AC, Fantozzi R. The role of histamine in neurogenic inflammation. $\mathrm{Br} \mathrm{J}$ Pharmacol. 2013;170(1):38-45.

46. Birklein F, Schmelz M. Neuropeptides, neurogenic inflammation and complex regional pain syndrome (CRPS). Neurosci Lett. 2008;437(3):199-202.

47. Artemiadis AK, Zis P. Neuropathic pain in acute and subacute neuropathies: a systematic review. Pain Physician. 2018;21:111-20.

48. Xanthos DN, Sandkuhler J. Neurogenic neuroinflammation: inflammatory CNS reactions in response to neuronal activity. Nat Rev Neurosci. 2014;15(1):43-53.

49. Barr AJ, Campbell TM, Hopkinson D, Kingbury SR, Bowes MA, Conaghan PG. A systematic review of the relationship between subchondral bone features, pain and structural pathology in peripheral joint osteoarthritis. Arthritis Res Ther. 2015;17:228. https://doi.org/10.1186/s13075-015-0735-x. 
50. Farrell M, Gibson S, McMeeken J, Helme R. Pain and hyperalgesia in osteoarthritis of the hands. J Rheumatol. 2000;27(2):441-7.

51. van Laar M, Pergolizzi JV Jr, Mellinghoff HU, et al. Pain treatment in arthritis-related pain: beyond NSAIDs. Open Rheumatol J. 2012;6:320-30.

52. Coaccioli S, Varrassi G, Sabatini C, Marinangeli F, Giuliani M, Puxeddu A. Fibromyalgia: nosography and therapeutic perspectives. Pain Pract. 2008;8:190-201.

53. Oliveira CB, Maher CG, Pinto RZ, Traeger AC, Lin CC, Chenot JF, van Tulder M, Koes BW. Clinical practice guidelines for the management of nonspecific low back pain in primary care: an updated overview. Eur Spine J. 2018;27(11):2791-803. https://doi.org/10.1007/s00586-018-5673-2 (Epub 2018 Jul 3. Review).

54. Roberts E, Delgado Nunes V, Buckner S, et al. Paracetamol: not as safe as we thought? A systematic literature review of observational studies. Ann Rheum Dis. 2016;75:552-9.

55. Nauta M, Landsmeer ML, Koren G. Codeine-acetaminophen versus nonsteroidal anti-inflammatory drugs in the treatment of post-abdominal surgery pain: a systematic review of randomized trials. Am J Surg. 2009;198:256-61.

56. Scarpignato C, Lanas A, Blandizzi C, Lems WF, Hermann M, Hunt RH. Safe prescribing of nonsteroidal anti-inflammatory drugs in patients with osteoarthritis-an expert consensus addressing benefits as well as gastrointestinal and cardiovascular risks. BMC Med. 2015;13:55.

57. Machado GC, Maher CG, Ferreira PH, et al. Efficacy and safety of paracetamol for spinal pain and osteoarthritis: systematic review and meta-analysis of randomized placebo-controlled trials. BMJ. 2015;350:h1225.

58. Da Costa BR, Reichenbach S, Keller N, et al. Effectiveness of non-steroidal anti-inflammatory drugs for the treatment of pain in knee and hip osteoarthritis: a network meta-analysis. Lancet. 2017;390(10090):e21-33.

59. Williams CM, Maher CG, Latimer J, et al. Efficacy of paracetamol for acute low-back pain: a doubleblind, randomised controlled trial. Lancet. 2014;384(9954):1586-96.

60. Ennis ZN, Dideriksen D, Vaegter HB, Handberg G, Pottegard A. Acetaminophen for chronic pain: a systematic review on efficacy. Basic Clin Pharmacol Toxicol. 2016;118:184-9.
61. NICE. Low back pain and sciatica in over $16 \mathrm{~s}$ : assessment and management [internet]. 2016. https://www.nice.org.uk/guidance/NG59/chapter/ Recommendations\#assessment-of-low-back-painand-sciatica.

62. Brooks PM, Day RO. Nonsteroidal anti-inflammatory drugs-differences and similarities. N Engl J Med. 1991;324(24):1716-25.

63. Tramŕr MR, Williams JE, Carroll D, Wiffen PJ, Moore RA, McQuay HJ. Comparing analgesic efficacy of non-steroidal anti-inflammatory drugs given by different routes in acute and chronic pain: a qualitative systematic review. Acta Anaesthesiol Scand. 1998;42:71-9.

64. Sarzi-Puttini P, Atzeni F, Lanata L, Bagnasco M. Efficacy of ketoprofen vs. ibuprofen and diclofenac: a systematic review of the literature and metaanalysis. Clin Exp Rheumatol. 2013;31:731-8.

65. Rainsford KD. Ibuprofen: from invention to an OTC therapeutic mainstay. Int J Clin Pract Suppl. 2013;178:9-20.

66. Catella-Lawson F, Reilly MP, Kapoor SC, et al. Cyclooxygenase inhibitors and the antiplatelet effects of aspirin. N Engl J Med. 2001;3345:1809-17.

67. John VA. The pharmacokinetics and metabolism of diclofenac sodium (Voltarol) in animals and man. Rheumatol Rehabil. 1979;Suppl 2:22-37.

68. Zuniga JR, Noveck RJ, Schmidt WK, Boesing SE, Hersh EV. Onset of action of diclofenac potassium liquid-filled capsules in dental surgery patients. Curr Med Res Opin. 2011;27:1733-9.

69. Schmidt M, Sørensen HT, Pedersen L. Diclofenac use and cardiovascular risks: series of nationwide cohort studies. BMJ. 2018;362:k3426.

70. Sarzi-Puttini P, Atzeni F, Lanata L, et al. Pain and ketoprofen: what is its role in clinical practice? Reumatismo. 2010;62(3):172-88.

71. Cimini A, Brandolini L, Gentile R, Cristiano L, Menghini P, Fidoamore A, Antonosante A, Benedetti E, Giordano A, Allegretti M. Gastroprotective effects of L-lysine salification of ketoprofen in ethanol-injured gastric mucosa. J Cell Physiol. 2015;230(4):813-20. https://doi.org/10.1002/jcp. 24809 (PMID: 25287669).

72. Brandolini L, d'Angelo M, Antonosante A, Villa S, Cristiano L, Castelli V, Benedetti E, Catanesi M, Aramini A, Luini A, Parashuraman S, Mayo E, Giordano A, Cimini A, Allegretti M. Differential protein modulation by ketoprofen and ibuprofen underlines different cellular response by gastric epithelium. J Cell Physiol. 2018;233(3):2304-12. 
https://doi.org/10.1002/jcp.26102 (Epub 2017 Aug 25 PMID: 28710861).

73. McCormack K, Brune K. Dissociation between the antinociceptive and anti-inflammatory effects of the nonsteroidal anti-inflammatory drugs. A survey of their analgesic efficacy. Drugs. 1991;41(4):533-47.

74. Burmester G, Lanas A, Biasucci L, et al. The appropriate use of non-steroidal anti-inflammatory drugs in rheumatic disease: opinions of a multidisciplinary European expert panel. Ann Rheum Dis. 2011;70:818-22.

75. Els C, Jackson TD, Hagtvedt R, et al. High-dose opioids for chronic non-cancer pain: an overview of Cochrane Reviews. Cochrane Database Syst Rev. 2017;10:CD012299.

76. Walker JS. Anti-inflammatory effects of opioids. Adv Exp Med Biol. 2003;521:148-60.

77. Chaparro LE, Furlan AD, Deshpande A, MailisGagnon A, Atlas S, Turk DC. Opioids compared with placebo or other treatments for chronic low back pain: an update of the Cochrane Review. Spine (Phila Pa 1976). 2014;39:556-63.

78. Jordan KM, Arden NK, Doherty M, et al. EULAR Recommendations 2003: an evidence-based approach to the management of knee osteoarthritis: report of a Task Force of the Standing Committee for International Clinical Studies Including Therapeutic Trials (ESCISIT). Ann Rheum Dis. 2003;62:1145-55.

79. Zhang W, Doherty M, Arden N, et al. EULAR evidence-based recommendations for the management of hip osteoarthritis: report of a task force of the EULAR Standing Committee for International Clinical Studies Including Therapeutics (ESCISIT). Ann Rheum Dis. 2005;64:669-81.

80. Dantzer R, O'Connor JC, Freund GG, Johnson RW, Kelley KW. From inflammation to sickness and depression: when the immune system subjugates the brain. Nat Rev Neurosci. 2008;9:46-56.

81. Zis P, Daskalaki A, Bountouni I, Sykioti P, Varrassi $G$, Paladini A. Depression and chronic pain in the elderly: links and management challenges. Clin Interv Aging. 2017;12:709-20.

82. Friebe A, Horn M, Schmidt F, et al. Dose-dependent development of depressive symptoms during adjuvant interferon-\{alpha\} treatment of patients with malignant melanoma. Psychosomatics. 2010;51:466-73.

83. Kohler O, Benros ME, Nordentoft M, et al. Effect of anti-inflammatory treatment on depression, depressive symptoms, and adverse effects: a systematic review and meta-analysis of randomized clinical trials. JAMA Psychiatry. 2014;71:1381-91.

84. White J, Kivimaki M, Jokela M, Batty GD. Association of inflammation with specific symptoms of depression in a general population of older people: the english longitudinal study of ageing. Brain Behav Immun. 2017;61:27-30.

85. Nazimek K, Strobel S, Bryniarski P, Kozlowski M, Filipczak-Bryaniarska I, Bryaniraski K. The role of macrophages in anti-inflammatory activity of antidepressant drugs. Immunobiology. 2017;222:823-30.

86. Attal N, Cruccu G, Haanpää M, et al. EFNS guidelines on pharmacological treatment of neuropathic pain. Eur J Neurol. 2006;13:1153-69.

87. Dickenson AH, Ghandehari J. Anti-convulsants and anti-depressants. Handb Exp Pharmacol. 2007;177:145-77.

88. Hummig W, Kopruszinski CM, Chichorro JG. Pregabalin reduces acute inflammatory and persistent pain associated with nerve injury and cancer in rat models of orofacial pain. J Oral Facial Pain Headache. 2014;28:350-9.

89. Moore RA, Straube S, Wiffen PJ, Derry S, McQuay HJ. Pregabalin for acute and chronic pain in adults. Cochrane Database Syst Rev. 2009;3:CD007076.

90. Rhen T, Cidlowski JA. Antiinflammatory action of glucocorticoids-new mechanisms for old drugs. N Engl J Med. 2005;353:1711-23.

91. Zhang W, Doherty M, Bardin T, et al. EULAR evidence based recommendations for gout. Part II: Management. Report of a task force of the EULAR Standing Committee for International Clinical Studies Including Therapeutics (ESCISIT). Ann Rheum Dis. 2006;65:1312-24.

92. Ramonda R, Oliviero F, Galozzi P, et al. Molecular mechanisms of pain in crystal-induced arthritis. Best Pract Res Clin Rheumatol. 2015;29:98-110.

93. Jackman RW, Rhoads MG, Cornwell E, Kandarian SC. Microtubule-mediated NF-kappaB activation in the TNF-alpha signaling pathway. Exp Cell Res. 2009;315:3242-9.

94. Misawa T, Takahama M, Kozaki T, et al. Microtubule-driven spatial arrangement of mitochondria promotes activation of the NLRP3 inflammasome. Nat Immunol. 2013;14:454-60.

95. Martinon F, Petrilli V, Mayor A, Tardivel A, Tschopp J. Gout-associated uric acid crystals activate the NALP3 inflammasome. Nature. 2006;440:237-41. 
96. Zhang B, Roh YS, Liang S, et al. Neurotrophin suppresses inflammatory cytokine expression and cell death through suppression of NF-kappaB and JNK in hepatocytes. PLoS One. 2014;9:e114071.

97. So A, De Smedt T, Revaz S, Tschopp J. A pilot study of IL-1 inhibition by anakinra in acute gout. Arthritis Res Ther. 2007;9:R28.

98. Terkeltaub R, Sundy JS, Schumacher HR, et al. The interleukin 1 inhibitor rilonacept in treatment of chronic gouty arthritis: results of a placebo-controlled, monosequence crossover, non-randomised, single-blind pilot study. Ann Rheum Dis. 2009;68:1613-7.

99. Zheng S, Hunter DJ, Xu J, Ding C. Monoclonal antibodies for the treatment of osteoarthritis. Expert Opin Biol Ther. 2016;16:1529-40.

100. Wang K, Xu J, Hunter DJ, Ding C. Investigational drugs for the treatment of osteoarthritis. Expert Opin Investig Drugs. 2015;24:1539-56.

101. LeGrand A, Fermor B, Fink C, et al. Interleukin-1, tumor necrosis factor alpha, and interleukin-17 synergistically up-regulate nitric oxide and prostaglandin E2 production in explants of human osteoarthritic knee menisci. Arthritis Rheum. 2001;44:2078-83.

102. Chevalier X, Giraudeau B, Conrozier T, Marliere J, Kiefer P, Goupille P. Safety study of intraarticular injection of interleukin 1 receptor antagonist in patients with painful knee osteoarthritis: a multicenter study. J Rheumatol. 2005;32:1317-23.

103. Varrassi G, Muller-Schwefe G, Pergolizzi J, et al. Pharmacological treatment of chronic pain-the need for CHANGE. Curr Med Res Opin. 2010;26:1231-45.

104. Varrassi G, Hanna M, Macheras G, et al. Multimodal analgesia in moderate-to-severe pain: a role for a new fixed combination of dexketoprofen and tramadol. Curr Med Res Opin. 2017;33:1165-73.

105. Gay-Escoda C, Hanna M, Montero A, et al. Tramadol/dexketoprofen (TRAM/DKP) compared with tramadol/paracetamol in moderate to severe acute pain: Results of a randomised, double-blind, placebo and active-controlled, parallel group trial in the impacted third molar extraction pain model (DAVID study. BMJ Open 9(2):bmjopen-2018023715. https://doi.org/10.1136/bmjopen-2018023715 .

106. Scholz J, Woolf CJ. Can we conquer pain? Nat Neurosci. 2002;5(Suppl):1062-7.
107. Stein C, Kuchler S. Targeting inflammation and wound healing by opioids. Trends Pharmacol Sci. 2013;34:303-12.

108. Kirtikara K, Swangkul S, Ballou LR. The analysis of nonsteroidal antiinflammatory drug selectivity in prostaglandin $\mathrm{G} / \mathrm{H}$ synthase (PGHS)-null cells. Inflamm Res. 2001;50:327-32.

109. Bannwarth B, Netter P, Pourel J, Royer RJ, Gaucher A. Clinical pharmacokinetics of nonsteroidal antiinflammatory drugs in the cerebrospinal fluid. Biomed Pharmacother. 1989;43:121-6.

110. Piirainen A, Kokki M, Hautajärvi H, Lehtonen M, Miettinen H, Pulkki K, Ranta VP, Kokki H. The cerebrospinal fluid distribution of postoperatively administred dexketoprofen and etoricoxib and their effect on pain and inflammatory markers in patients undergoing hip arthroplasty. Clin Drug Investig. 2016;36(7):545-55. https://doi.org/10. 1007/s40261-016-0400-4.

111. Ossipov MH, Jerussi TP, Ren K, Sun H, Porreca F. Differential effects of spinal (R)-ketoprofen and (S)ketoprofen against signs of neuropathic pain and tonic nociception: evidence for a novel mechanism of action of (R)-ketoprofen against tactile allodynia. Pain. 2000;87:193-9.

112. Diaz-Reval MI, Ventura-Martinez R, Deciga-Campos M, Terron JA, Cabré F, Lopez-Munoz FJ. Evidence for a central mechanism of action of S-(+)-ketoprofen. Eur J Pharmacol. 2004;483:241-8.

113. Gynther M, Jalkanen A, Lehtonen M, et al. Brain uptake of ketoprofen-lysine prodrug in rats. Int J Pharm. 2010;399:121-8.

114. Hodkinson DJ, Khawaja N, O'Daly O, et al. Cerebral analgesic response to nonsteroidal anti-inflammatory drug ibuprofen. Pain. 2015;156:1301-10.

115. Salvo F, Fourrier-Réglat A, Bazin F, et al. Cardiovascular and gastrointestinal safety of NSAIDs: a systematic review of meta-analyses of randomized clinical trials. Clin Pharmacol Ther. 2011;89:855-66.

116. Scarpignato C, Hunt RH. Nonsteroidal antiinflammatory drug-related injury to the gastrointestinal tract: clinical picture, pathogenesis, and prevention. Gastroenterol Clin North Am. 2010;39:433-64.

117. Castellsague J, Riera-Guardia N, Calingaert B, et al. Individual NSAIDs and upper gastrointestinal complications: a systematic review and meta-analysis of observational studies (the SOS project). Drug Saf. 2012;35:1127-46. 
118. Lewis SC, Langman MJ, Laporte JR, Matthews JN, Rawlins MD, Wiholm BE. Dose-response relationship between individual nonaspirin nonsteroidal anti-inflammatory drugs (NANSAIDs) and serious upper gastrointestinal bleeding: a meta-analysis based on individual patient data. Br J Clin Pharmacol. 2002;54:320-6.

119. Laporte JR, Ibanez L, Vidal X, Vendrell L, Leone R. Upper gastrointestinal bleeding associated with the use of NSAIDs: newer versus older agents. Drug Saf. 2004;27:411-20.

120. Rostom A, Moayyedi P, Hunt R. Canadian consensus guidelines on long-term nonsteroidal anti-inflammatory drug therapy and the need for gastroprotection: benefits versus risks. Aliment Pharmacol Ther. 2009;29:481-96.

121. Broekmans S, Dobbels F, Milisen K, Morlion B, Vanderschueren S. Medication adherence in patients with chronic non-malignant pain: is there a problem? Eur J Pain. 2009;13(2):115-23. https:// doi.org/10.1016/j.ejpain.2008.02.010 (Epub 2008 May 7).

122. Markotic F, Cerni Obrdalj E, Zalihic A, Pehar R, Hadziosmanovic Z, Pivic G, Durasovic S, Grgic V, Banozic A, Sapunar D, Puljak L. Adherence to pharmacological treatment of chronic nonmalignant pain in individuals aged 65 and older. Pain Med. 2013;14(2):247-56. https://doi.org/10.1111/ pme.12035 (Epub 2013 Jan 31).

123. Park KK, Choi CH, Ha CW, Lee MC. The effects of adherence to non-steroidal anti-inflammatory drugs and factors influencing drug adherence in patients with knee osteoarthritis. J Korean Med Sci. 2016;31(5):795-800. https://doi.org/10.3346/jkms. 2016.31.5.795 (Epub 2016 Mar 29).

124. Stoll B, Henry J, Reeds PJ, Yu H, Jahoor F, Burrin DG. Catabolism dominates the first-pass intestinal metabolism of dietary essential amino acids in milk protein-fed piglets. J Nutr. 1998;128:606-14.

125. Marmo E, Ottavo R, Giordano L, et al. Experimental assessment of some pharmacodynamic features of ketoprofen lysine. Pain relief activity, antipyretic effects, anti-inflammatory activity, anti-platelet aggregation activity and interference with the biosynthesis of prostaglandins. Arch Sci Med (Torino). 1980;137:387-404.

126. Nalamachu S, Pergolizzi JV, Raffa RB, Lakkireddy DR, Taylor R Jr. Drug-drug interaction between NSAIDs and low-dose aspirin: a focus on cardiovascular and GI toxicity. Expert Opin Drug Saf. 2014;13:903-17.

127. Hohlfeld T, Saxena A, Schrör K. High on treatment platelet reactivity against aspirin by non-steroidal anti-inflammatory drugs-pharmacological mechanisms and clinical relevance. Thromb Haemost. 2013;109:825-33.

128. Saxena A, Balaramnavar VM, Hohlfeld T, Saxena AK. Drug/drug interaction of common NSAIDs with antiplatelet effect of aspirin in human platelets. Eur J Pharmacol. 2013;721:215-24.

129. McGettigan P, Henry D. Cardiovascular risk and inhibition of cyclooxygenase: a systematic review of the observational studies of selective and nonselective inhibitors of cyclooxygenase 2. JAMA. 2006;296:1633-44.

130. Bhatt DL, Scheiman J, Abraham NS, et al. ACCF/ ACG/AHA 2008 expert consensus document on reducing the gastrointestinal risks of antiplatelet therapy and NSAID use: a report of the American College of Cardiology Foundation Task Force on Clinical Expert Consensus Documents. Circulation. 2008;118:1894-909.

131. Final Report Summary-SOS (Safety of non-steroidal anti-inflammatory drugs). SOS project. [Internet]. ROTTERDAM (Netherlands) 2013. http:// cordis.europa.eu/result/rcn/54210_it.html.

132. Sondergaard KB, Weeke P, Wissenberg $M$, et al. Non-steroidal anti-inflammatory drug use is associated with increased risk of out-of-hospital cardiac arrest: a nationwide case-time-control study. Eur Heart J Cardiovasc Pharmacother. 2017;3:100-7.

133. Gulmez SE, Moore N, Pageaux GP, et al. Causality of drugs involved in acute liver failure leading to transplantation: results from the study of acute liver transplant (SALT). Drug Saf. 2013;36:757-64. 